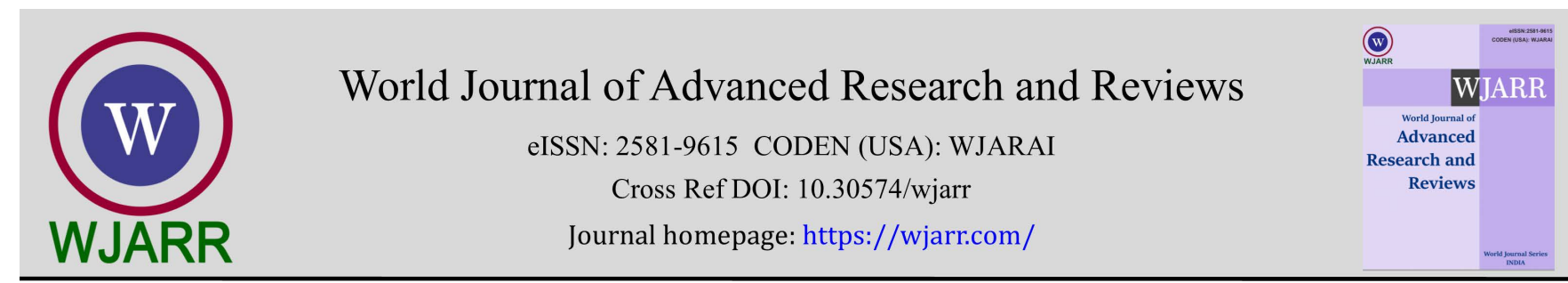

(REVIEW ARTICLE)

Check for updates

\title{
Senior citizens in Nepal are in desperate need
}

\author{
Nawa Raj Subba * \\ Purbanchal University, Edenburgh International College, Biratnagar-16, Nepal.
}

World Journal of Advanced Research and Reviews, 2021, 10(02), 176-183

Publication history: Received on 03 April 2021; revised on 09 May 2021; accepted on 11 May 2021

Article DOI: https://doi.org/10.30574/wjarr.2021.10.2.0206

\section{Abstract}

This review paper looked at some of the most relevant material on senior citizens' issues. The study aimed to use secondary data analysis to determine the most pressing needs of senior citizens. The essay examined their current situation, problems, and needs. Nepal's elderly population is growing every year. They have not received adequate care from the government. The private sector made a considerable contribution to this endeavor. Both the government and the private sector have made efforts in this regard. They are currently battling to meet their basic requirements. Senior citizens not receiving adequate food and has disability mental illnesses are two of the several misfortunes listed in the research papers, both of which are public health concerns. They are in dire need of proper nutrition as well as mental health promotion. That is an area where both the government and the private sector can focus. COVID-19 has the highest Case Fatality Rate among elderly adults, and Nepalese senior citizens have a high mortality rate. The high mortality and fatality rates of COVID among the elderly have prompted policymakers to focus on senior citizens' health and living conditions. There are three tiers of government in Nepal. If they understand the issue, they will develop strategies and services to aid senior citizens. In this changing environment, the public and private sectors at various levels must enhance cooperation to improve the dreadful situation of senior citizens. Also, the importance of family in senior citizen care has grown in recent years.

Keywords: Senior citizens; Elderly adults; Urgent needs; Mental health problem; Malnutrition; Vriddhashram.

\section{Introduction}

\subsection{Demographic background}

In $2011,11 \%$ of the global population was over 60 years old. At the time, 8.1 percent of Nepal's total population was over the age of 60. In 1961, Nepal's senior citizen population was just 5.2 percent [1]. The senior citizens' proportion in the population is steadily growing. The increase in access to health care and the rise in living standards in the country are extensive reasons for such changes in the demographic structure and the increase in the proportion of senior citizens.

Multifaceted efforts have resulted in an improvement in the population's average life expectancy. Nepali, on average, are 66.6 years old, according to the 2011 census [2]. The world's average age, including Nepal's, has risen in recent years. As a result, the percentage of people over the age of 60 has increased steadily. By 2050, the people over the age of 60 proportion would hit $22 \%$ of the total population if current population growth continues at its current pace and the average age of the population rises [3]. As a result, the rate of family dependence will rise. To put it another way, those in the earning age group would have to work harder to support the family. On the other hand, the state would be responsible for a considerable amount of economic and social obligation to meet the demands and needs of those over the age of 60 .

\footnotetext{
* Corresponding author: Nawa Raj Subba

Purbanchal University, Edenburgh International College, Biratnagar-16, Nepal. 
We must all be willing to recognize the growing obligations toward senior citizens as both opportunities and challenges.

\subsection{Study type and data}

It's a thematic revisit that looks at social and health-related issues of senior citizens from a public health perspective. It has conducted a critical examination of the subject's sociopolitical and cultural aspects. This review has based on secondary data, both qualitative and quantitative. The researcher visited a comprehensive dataset to conclude by reanalyzing previously collected and analyzed data. The researcher used an online search tool to look for current facts to learn more about the issues that concern elderly adults, including the effects of the COVID-19 pandemic.

\section{Methodology}

Table 1 Thematic key analysis.

\begin{tabular}{|l|l|}
\hline Themes & Key issues \\
\hline Identification of senior citizen & Definition by law \\
\hline Government role on senior citizen & $\begin{array}{l}\text { Provision of law, plans, strategy, programs. } \\
\text { Examine the areas where there is space for change. }\end{array}$ \\
\hline Private sector role on senior citizen & $\begin{array}{l}\text { The state of an elderly care home. Constraints and issues } \\
\text { Assessment of the source of funding for elderly care homes. } \\
\text { Interested both personally and institutionally. } \\
\text { Experience of senior citizens living in an elderly care home. } \\
\text { Is there anything that needs to do there? }\end{array}$ \\
\hline Quantitative data analysis & $\begin{array}{l}\text { Senior citizen related Public health issues, living condition, } \\
\text { nutrition, mental health illness, COVID-19 }\end{array}$ \\
\hline Qualitative data analysis & $\begin{array}{l}\text { Assessing the care of senior citizens' problem. } \\
\text { Demand, need, and gap identification. }\end{array}$ \\
\hline Identifying senior citizens' urgent needs & By critical analysis of the pieces of evidence. \\
\hline
\end{tabular}

Above mentioned themes and core issues influenced the search and learning of the literature review.

Table 2 Document inclusion and exclusion requirements for critical analysis.

\begin{tabular}{|l|l|}
\hline Documents & Requirements \\
\hline Included & $\begin{array}{l}\text { Documents published between } 1996 \text { and } 2021 . \\
\text { Original studies, research, review, report, bulletin, law, plan, analysis. } \\
\text { Search words: Senior citizen Nepal, Public health indicators of elderly } \\
\text { adults, Vriddhashram related data, Qualitative and quantitative data } \\
\text { on senior citizens, Quality of life, Primary Health Care. } \\
\text { Documents published in English, Laws \& regulation published in } \\
\text { Nepali. }\end{array}$ \\
\hline Excluded & $\begin{array}{l}\text { There are no records of senior citizens in the documents. The studies } \\
\text { in the main text lacked supporting evidence. } \\
\text { Newspaper news, stories, and editorial records are not included. }\end{array}$ \\
\hline
\end{tabular}

The reviewer screened the documents' abstracts and full-texts. The process of inclusion and exclusion has focused on the review's stated criteria. 
Table 3 Process of article selection.

\begin{tabular}{|l|l|ll|}
\hline Identification & The article, documents identified (124) & \\
\hline Abstraction & Abstracts scanned (124) & Abstracts excluded (49) \\
\hline Eligibility & Full-text articles assessed (75) & $\begin{array}{l}\text { Full-text articles excluded upon } \\
\text { requirements (50) }\end{array}$ \\
\hline Inclusion & $\begin{array}{l}\text { Studies and documents included in the final } \\
\text { analysis and synthesis (25) }\end{array}$ & \\
\hline
\end{tabular}

\section{Discussion}

\subsection{Definition of senior citizen}

The genetic theory defines aging as determined by DNA. Psychosociobiological theory defines senior citizens based on age-related changes such as age, changes in family and society roles, and loss of physical and mental capacity [4]. The state has defined senior citizens at the legal level to provide tangible information to the general public about the population structure to ensure accountability towards them. The Senior Citizens Act of Nepal, 2006 defines a senior citizen who has reached the age of 60 years. The act has also defined helpless senior citizens. A helpless senior citizen is defined as a person who has no basis of livelihood, no source of income or property, no member of the family to nurture and care for, and even if she or he is a family member, a senior citizen not looked after by the family is a vulnerable senior citizen. Besides, the act defines physically and mentally disabled senior citizens as 'disabled senior citizens' [5]. The above-mentioned definition of the senior citizen has facilitated the management of senior citizens based on their living conditions.

\subsection{Public and private sector participation in senior citizen care}

Nepal society and the state seem to be concerned and responsible for the senior citizens. It seems that the Government of Nepal has been putting forward welfare concepts and programs for the protection of senior citizens for a long time. The government has introduced the concept of a 'day service center' to spend the afternoon or take care of the senior citizens. It takes care of the senior citizens in the afternoon with or without a fee. Day Service Center shall mean the houses, Ashrams, or other structures of similar nature established and operated by the act [5]. Currently, the state has timely modified the concept of 'daycare center' targeting senior citizens.

Senior citizens are cared for in the care center with or without a fee. The elderly care center is also known as a Vriddhashram. For a long time, the Pashupatinath Vriddhashram has been caring for senior citizens in the Pashupatinath temple complex in the government sector. In addition to Kathmandu, there are Vriddhashrams in Bhaktapur, Nuwakot, and Makwanpur districts. In Province-1, Tamar Mulghat Vriddhashram in Dhankuta, Birateshwar Vriddhashram in Biratnagar, Kankai Mai Vriddhashram in Jhapa, Bhubaneswari Vriddhashram in Budhiganga-1, Morang, and Madhumalla Vriddhashram Morang are in operation. Similarly, Vriddhashrams are also operating in the Sunsari and Sankhuwasabha districts of the state. There are Vriddhashrams in Devghat of Tanahu, Sitapaila of Kaski, and Myagdi in Province-4. There are Vriddhashrams in Kailali and Kanchanpur districts in Province-7 [6]. So far, 82 institutions have been registered as Vriddhashram in the Government of Nepal. It has a seating capacity of about 1,500 elderly people. The Government of Nepal operates the Pashupatinath Vriddhashram with a capacity of 230 senior citizens. This suggests that the private sector provides more care to senior citizens than the government sector [7].

According to the NHRC assessment, there are five types of resources available for running a Vriddhashram in Nepal. The first type of resource is government grants. The second type of resource is voluntary donations, commodities, etc. collected from individual initiatives. The third type of resource is the support of an indigenous organization. The fourth type of resource is the support of an international organization. The monetary assistance of non-resident Nepali organizations based in various countries is the fifth form of resource [7]. Thus, the resources of the Vriddhashram and daycare center have been arranged with the help of the government and the private sector.

A study conducted in 2018 showed that the condition of privately run Vriddhashram was better than in the governmentrun one. The study also suggested to the government to focus on the management of government-run care centers and Vriddhashram [8]. So far, the state does not have up-to-date statistics on the progress of government and private sector programs and services related to the care of senior citizens. Ministry of Women, Children, and Senior Citizens have 
initiated to implement the data collection and updated working procedure of senior citizens-2077 only in September 2020 [9]. The Ministry is currently updating data on senior citizens.

Nepal's Census-2021 has scheduled to take place in June 2021 [10]. The census report will give a picture of senior citizens. The critical data system for senior citizens would improve by both the source and procedure. As a result, tangible senior citizen programs will implement soon. Hopefully, the tailored program will help target senior citizens. And information about the services they receive will be maintained regularly. At present, to obtain the necessary information about this, it is necessary to rely on the results of various studies and researches done in this field so far.

Ministry of Women, Children, and Senior Citizens care for Senior citizens. Ministry of Health provides health services and the Ministry of Agriculture is responsible for food and nutrition. The Ministry of Home Affairs administers the senior citizens' organizations. As a result, several ministries are active in providing senior citizen services. The issue now is who can give and arrange the proper programs for senior citizens, which is also a policy issue. Both the federal government and local governments have a lot of research to do. The challenge has to move the service ahead in a coordinated way without allowing duplication between the bodies on the issue of senior citizens.

\subsection{Provisions made by the state for senior citizens}

The Constitution of Nepal-2015 has established social security as a part of basic human rights. Before that social security issues were included in the Periodic Plan and Five Year Plan (1955 to 1997) operated in Nepal. The Government of Nepal had also introduced special programs for the helpless, disabled, widows, and senior citizens in the year 19972002 scheme. The Tenth Plan (2002-2007) emphasized ensuring social security for senior citizens. The three-year plan (2007-08-2009) emphasized legal provisions to ensure the rights and entitlements of senior citizens. The 2011-2013 plan, on the other hand, provided clear concepts and programs for senior citizens [11].

Nepal has made provisions in the Civil Act of 2018 and the Senior Citizens Act of 2006 to make sure senior citizens' rights and entitlements. The Senior Citizens Rules, 2008, have also been made available. This provision has protected the senior citizens' economic interests. Besides, the Local Self-Government Act of 2017, the Senior Citizens Policy of 2001, and the National Plan of 2005 have outlined a long-term strategy for ensuring senior citizens' rights and entitlements [11].

There seems a lot of experience on the international and national levels for senior citizens' rights and interests. We will have to wait for the results for a little longer. However, the local government has yet to develop a service for senior citizens. The local government needs to develop a strategy, short and long-term plans for senior citizens.

\subsection{Quality of life and primary health care}

In a study conducted in Kailali Nepal, $45.9 \%$ of the elderly said their quality of life (QOL) was neutral (neither good nor bad), 35.1 percent said it was good, and 19.0 percent said it was needy. Furthermore, educational status and land/property ownership positively correlated with QOL. In the report, Age, gender, marital status, household size, elderly violence, poor living arrangements, and physical health status negatively corresponded with QOL [12].

There have been studies on the health status and living standards of senior citizens in Nepal. The results of the Senior Citizens Study conducted in the Far Western Development Region, now known as province-7, will make it easier to understand the situation of Nepal's senior citizens [13]. Among the senior citizens living in the Far West Development Region, a sample of 325 senior citizens was asked a questionnaire and an observational study was conducted. The study involved senior citizens in the age group of 60 to 80 years. According to the study, 67 percent of respondents reported the primary source of income was agribusiness. Looking at their marital status, about one-third, or 33 percent, of senior citizens were widows or widowers. Out of 325 respondents, 87 percent of senior citizens lived in joint families. Nine percent of senior citizens were separated from joint families. According to the study report, only 35 percent of the senior citizens had toilet facilities in their homes. Of those senior citizens, only 63 percent had safe drinking water in their homes. More than half, or 57 percent of senior citizens, did not have a separate bedroom. This figure demonstrates that senior citizens were deprived of even the most basic public health requirements.

In a study conducted in Nepal's Far West Region, less than two-thirds, or 67 percent of senior citizens surveyed were happy with their families. More than a third of senior citizens, or 37 percent, were unhappy with their families. When the surveyor asked about their habits, more than half, or 56 percent, admitted to using tobacco or alcohol. Sixty-five percent of seniors engaged in physical activity or helping household chores. According to the survey, only 57 percent of senior citizens consumed two meals a day. When questioned further, less than half, or $48 \%$ said they were pleased with 
their meals, while more than half, 52\% said they did not have enough food to eat on time [13]. This statistic indicates how vulnerable senior citizens were, as they did not receive even two meals a day.

Ninety-three percent of those surveyed said they had an eye problem. Eighty percent said they had dental issues, while 54 percent said they had digestive issues. Forty-five percent of senior citizens said they had lung disease, and 19 percent said they had heart disease. Just $17 \%$ of them had regular health screenings. Thus, senior citizen's reliance on their family and poor economic situation were the primary reasons for the lack of access to routine health check-ups [13]. This data illustrates that senior citizens were forced to die prematurely due to poor access to healthcare.

Above were the village's stories. There hasn't been enough research done on the city's suffering. A new generation has moved to developed countries to study and work as a result of current globalization. They are increasingly opting to get citizenship and live permanently in another country. Senior citizens, however, are left alone at home. The children have to look after the elderly and provide medical care as they get older, but they are not available at home. And if children take them overseas, their minds are unhappy. It's a deplorable scene. The article would be incomplete without mentioning a new social problem. More children than the government should consider how to fix the problem humanely.

\subsection{A story of a senior citizen woman}

The following is a summary of the interview taken by Mishra and Chalise as part of a study's qualitative data collection [8]. It can encapsulate the real situation of many senior women. The study's qualitative data shows Bhakta Kumari Shrestha's life story and heartache (name change). On the day her husband died, Bhakta Kumari, who lives in Dhading, Nepal, lost her fortune. The daughter had married and moved to her family. The uneducated and poor widow was left alone at home. Bhakta Kumari has been devastated by her husband's death. Instead of being encouraged and embraced in society, her immediate family and community put her aside. She is now residing in a government-assisted Vriddhashram.

When asked what the issue was, she expressed her dissatisfaction with the poor sanitation of the toilet in the Vriddhashram. Her body aches at times, and her knee gets pain at other times. Caregivers are also making her nervous when reporting for treatment. She enjoys eating meat on occasion. She fulfills her wish by purchasing a plate of meat outside the hotel once a month. It was possible with money provided to her by her daughter when she visits. "Maybe it's just my luck! I now wish to die here, regardless of the consequences," she said with a long sigh. She also expressed the message that she is counting forward to her death [8].

When I saw the word picture, my writer's heart broke. I've seen a lot of these women in Vriddhashram. Some capable children have also taken their elderly parents to the facility. Even though their stories are distinct, the underlying theme is that elderly are in a fragile state.

\subsection{Effects of malnutrition on mental illness, and life satisfaction}

A hospital-based study has determined the connection between senior citizens' nutritional status and mental health issues in Nepal. The study established a link between malnutrition and depression in senior citizens. The senior citizen's satisfaction with life depends upon her or his nutritional and mental health status [14]. Not only that, but malnutrition triggers infectious and chronic diseases in the elderly. Malnutrition causes mental disorders. Thus, malnutrition and mental wellbeing play a critical role in senior citizens' self-satisfaction [6].

According to studies conducted on cost-benefit on health, senior citizens' health is reasonably good in countries where the government spends the requisite amount on health care [15]. Nepal has low spending on health compared to other developed and developing countries. Senior citizen services will have affected due to the inadequate budget investment. This is something that the government needs to concern with.

The global forum has raised the issues of hunger and mental health treatment for senior citizens. At the international level, Nepal has also expressed its commitment in this regard. The World Food Program, which met in Rome in 1992 has declared hunger and malnutrition are intolerable [16]. Special attention to the nutritional status of children and senior citizens in underdeveloped and developing countries should pay, according to the Rome International Conference on Nutrition. The Conference has urged member states to develop a variety of nutrition initiatives to make sure meeting their dietary needs.

Nepal's health policies and services have prioritized children and women. Senior citizens are now one of the target groups. However, the service they receive is solely the medical treatment of chronic illnesses. Senior citizens' service 
has confined to blood pressure check-up and chronic disease treatment. The senior citizens' public health service has a narrow approach. It needs to widen. The senior citizen service mentioned in the policy becomes meaningful only when we provide health services, including nutrition and mental health promotion.

\subsection{The burden of mental illness}

The elderly 93 percent had health problems, according to a study conducted in Devghat, Chitwan, Nepal. 86 percent of the elderly self-reported their health as fair. The study calculated the average functional disability score was 2.53 $( \pm 2.05)$. Depression has affected $57.8 \%$ of the population. 46.7 percent were mildly depressed, 8.9 percent were moderately depressed, and 2.2 percent depressed severely [17].

Another study in Pokhara found that 44.2 percent of students suffer from depression. Among them, 25.3 percent of students were diagnosed with mild depression, and 18.9 percent with severe depression [18]. It's now worth noting the figure listed in the government program. Mental disorder, however, accounts for just $18 \%$ of the non-communicable disease burden in Nepal, according to the government's Multi-sectoral Action Plan for the Prevention and Control of Non-Communicable Diseases, 2014-2020 [19]. As seen in the above data, there is a real gap between the evidence used at the policy level and the findings of independent researchers. This imbalance has also affected policymaking. The Nepal government is currently undertaking mental health survey. We should expect something, but the time it will take for the plan, initiative, or program to reach the target group based on statistics is still a concern.

To better understand elderly adults' health needs and treatment, the qualitative research has divided them into three groups: healthy and active, treating diseases, and sick [20]. The study found that each expectation of well-being, not just counts of chronic diseases, was critical. The health management system should take a holistic approach to improve health outcomes and promote healthier aging. The classification and psychological aspects of senior citizens are the focus of the research. The researcher believes that their management should take a multi-faceted approach. A study conducted in India assessed the death anxiety scale using the Daily Spiritual Experience Scale, General Health Questionnaire 28 (GHQ-28), and Thakur Death Anxiety Scale. Spiritual belief and good mental health link to result in low levels of death anxiety. According to the report, mental health professionals should promote spirituality to help people cope with death anxiety [21]. Studies suggest physical activity is good for senior citizens over the age of 74 . Physical exercise by senior citizens promotes good health and longevity [22, 23].

Physical activity and spiritual practice are beneficial to senior citizens, according to studies.

In Nepal, most Vriddhashrams have built-in religious pilgrimage sites. Our forefathers and mothers did not select this place solely to make their funerals more convenient in their later years. Studies have shown that living in a religious place reduces the anxiety of death. It is meaningful that our forefathers' vision has realized the spiritual wellbeing of the elderly. We can consider this criterion when deciding where to develop a Vriddhashram in the future.

\subsection{COVID-19 has a terrible impact on senior citizens}

The COVID-19 pandemic has disproportionately affected senior citizens in Nepal. It infected 29016 elderly adults, 10.33 percent of the total COVID-19 infection of 280956 people until April 15, 2021. Nepal Government's official report has covered the period from the onset of the outbreak, January 23, 2020, to April 15, 2021. According to the dataset, the deaths of the elderly accounted for 1920 deaths, 62.72 percent of 3061 total deaths [24]. In China, the COVID-19 Case Fatality Rate (CFR) for the 80+ age group was 14.8 percent, for the $70-79$ age, it was $8 \%$, and for the $60-69$ age group, it was 3.6 percent. In the $20-40$-year-old, it was 0.32 percent, 0.18 percent in the $10-19$-year-old group, and 0 percent in the under 9-year-old group [25]. As a result, the elderly have the highest number of fatalities. The COVID-19 mortality and fatality rate among senior citizens call for urgent action to improve senior citizens' quality of life, social security, and access to healthcare.

I argue that senior citizens' high mortality rate is due to more than just their physical state. Malnutrition, mental illness, chronic diseases, and low living standards all give to this unfortunate outcome. Senior citizens have got priority in the COVID-19 coronavirus vaccination program, which is the right strategy. Senior citizens, who will be at the frontline of every potential outbreak, like COVID, need improvements in public health, social welfare, and living conditions. Government should prioritize goals, policies, strategies, plans, and services for treating their malnutrition and mental health problems.

In Nepal, nevertheless, the government develops policies and programs, they are ineffective. Even though the Nepal government introduced mental health policies in 1996 and 2017, they could not carry out them successfully. The Ministry of Health and Population's institutional arrangement for mental health care has not yet reached the community 
level. Furthermore, the general community has stigmatized mental health disorders. People suffering from anxiety and depression have been unable to seek treatment. This disorder could have treated with simple counseling.

\section{Conclusion}

According to the facts and evidence presented above, senior citizens in Nepal do not receive adequate, well-balanced nutrition. Their physical and emotional well-being has received insufficient attention. The primary caretakers are the family, society, and the government. Seniors become mentally ill when they are subjected to family disappointment and socioeconomic stress. As a result, senior citizens experience anxiety, depression, and dementia. As a measure, the family, community, and government should pay particular attention to the nutritional and mental health of the elderly. Furthermore, COVID-19 has the highest Case Fatality Rate among elderly adults, and Nepalese senior citizens had a high mortality rate. It allows planners to concentrate on improving the health and living conditions of senior citizens. At the moment, Nepal has three levels of government. If they grasp the root of the issue, they will help senior citizens by developing policy, strategy, and program. Besides, family members should take responsibility, realizing that senior citizens are not a burden in a family but a source of pride. If people do not behave humanely, the government and the private sector alone cannot solve this problem. The role of the family in senior citizen management has increased today more than yesterday.

\section{Compliance with ethical standards}

\section{Acknowledgments}

Sitaram Dhakal, a social worker made me mindful of senior citizens' problems, which I appreciate. I am also grateful to Biratnagar Vriddhashram's Jagat Aryal for providing me with details.

\section{References}

[1] CBS. Nepal Population and Housing Report. Central Bureau of Statistics, National Planning Commission, Kathmandu, Nepal. 2011.

[2] MoHP. Nepal Population Report. Ministry of Health and Population, Population Division, Kathmandu, Nepal. 2011.

[3] UN. World Population Ageing. UN. 2019 December.

[4] Rogers K, Guarente, Leonard P, Simic P. Aging. Encyclopedia Britannica. 2020.

[5] NLC. Senior Citizen Law-2063. Nepal Law Commission, Kathmandu, Nepal. 2006.

[6] Adhikari S. Health, Nutrition, and Care for Senior Citizens of Nepal in Twenty-First Century. JHAS. 2013; 3(1): 7375.

[7] NHRC. Human Rights Journal: Senior Citizen Special Issue. Sambahak. Nepal Human Rights Commission. 2018; 10 .

[8] Mishra S, Chalise HN. Health status of elderly living in government and private old age homes in Nepal. Asian Journal of Biological Science. 2018; ISSN 1996-3351.

[9] MOWCSC. Ministry of Women, Children, and Senior citizen. Official website notice. 2021.

[10] CBS. Central Bureau of Statistics official. Official website Notice, Nepal Planning Commission, Kathmandu, Nepal. 2021.

[11] Bhandari K. Social Security System of Elderly Population in Nepal. NUTA JOURNAL. 2018; 6 (1\&2): 2075 : ISSN: $2616-017 \mathrm{x}$

[12] Joshi MR, Chalise HN, Khatiwada PP. Quality of Life of Nepalese Elderly Living in Rural Nepal. Journal of Gerontology \& Geriatric Research; Res. 2018; 7: 5.

[13] Bhatta R. Social and Health Status of Elderly Population in Far-Western Region. A research report was submitted to Nepal Health Research Council in Kathmandu, Nepal. 2009; 38.

[14] Ghimire S, Baral BK, Karmacharya I, Callahan K, Mishra SR. Life satisfaction among elderly patients in Nepal: associations with nutritional and mental well-being. BMC Health Qual Life Outcomes. 2018; $16: 118$. 
[15] Cachioni M, Cipolli GC, Borim FS, Batistoni SS, Yassuda MS. Factors Associated With Positive Self-Rated Health: Comparing Older Adults in Brazil and Portugal. Frontiers in Public Health. 2021; 9: 258

[16] FAO. World Food Summit, 13-17 November 1998, Rome Italy. Food Agricultural Organization of the UN. 1998.

[17] Chalise HN. Depression among elderly living in Vriddashram (old age home). Advances in Aging Research. 2014; $3(1)$.

[18] Bhattarai D, Shrestha N, Paudel S. Prevalence and factors associated with depression among higher secondary school adolescents of Pokhara Metropolitan, Nepal: a cross-sectional study. BMJ Open 2020; 10: e044042.

[19] NHRC. National Mental Health Survey-2021. Nepal: Project Status. Government of Nepal, Nepal Health Research Council. 2021.

[20] Tkatch R, Musich S, MacLeod S, Kraemer S, Hawkins K, Wicker ER, Armstrong DG. A qualitative study to examine older adults' perceptions of health: Keys to aging successfully. Geriatric Nursing. 2017; 38(6): 485-490.

[21] Nagaraj M, Nithyanandan DV. Death Anxiety and Psychological Wellbeing of Institutionalized Elderly: Relationship, Association, and Influences of Demography. Indian Journal of Gerontology. 2019; 33(3): 255-267.

[22] Hirsch CH, Diehr P, Newman AB, Gerrior SA, Pratt C, Lebowitz MD, Jackson SA. Physical activity and years of healthy life in older adults: results from the cardiovascular health study. Journal of Aging and Physical Activity. 2010; 18(3): 313-334.

[23] Taylor D. Physical activity is medicine for older adults. Postgraduate Medical Journal. 2014; 90(1059): 26-32.

[24] MoHP. Public Health Bulletin. Ministry of Health and Population, Kathmandu, Nepal. 15 March 2021.

[25] Braden M, Aradhya S, Kolk M, Harkonen J, Drefahl S, Malmberg B, Rostila M, Cederstrom A, Andersson G. Residential context and COVID-19 mortality among adults aged 70 years and older in Stockholm: a populationbased, observational study using individual-level data Eleonora Mussino. Lancet Healthy Longev. 2020; 1: 8088.

\section{Author's short biography}

\begin{tabular}{|l|l|}
\hline Nawa Raj Subba is a public health specialist who has written books and research \\
articles. He has recently published some books and articles on the subject of Kirat \\
culture. Public health and intercultural psychology are two of his research and writing \\
interests. He has many books and music albums written in the field of literature, and \\
he also enjoys creative writing. He holds a doctorate in health psychology and a \\
master's degree in public health and Nepali literature. Culture, anthropology, \\
sociology, and population are among the subjects he has studied. On the experience \\
front, he has served as a District Public Health Officer for the Ministry of Health and \\
Population of the Government of Nepal for more than three decades.
\end{tabular}

